\section{Memoria, justicia y verdad en la masacre de El Mozote}

\author{
María Sol Yáñez (Universidad Centroa- \\ mericana "José Simeón Cañas") y Amalio \\ Blanco (Universidad Autónoma de Madrid)
}

Apenas queda un rato de oscuridad.

Todavía no he dormido. Pensaba en el futuro. No en cualquier futuro en cualquier parte. Ni en nuestro futuro juntos. Pensaba en el futuro que intentan abortar aquí. No lo lograrán. El futuro que ellos temen llegará. Y lo que quedará en él de nosotros es la confianza que mantuvimos en la oscuridad.

John Berger

\section{Resumen}

En 2010, las víctimas de El Mozote presentaron una demanda ante la Corte Interamericana de Derechos Humanos, que requirió de un peritaje psicosocial. Este peritaje fue realizado por la primera firmante de este artículo. Sus resultados han mostrado el horror vivido por las víctimas, el daño causado a mujeres, niñas y niños, la destrucción de las redes familiares y comunitarias, las persistentes secuelas psicológicas, el desplazamiento a que dio lugar y la incesante lucha contra la impunidad a fin de hacer brillar la verdad. En este artículo, se lleva a cabo una lectura de los resultados de dicho peritaje enmarcándolos dentro de los acontecimientos de la guerra civil de El Salvador y de las investigaciones y aportes teóricos enmarcados: a) en los postulados teóricos de la memoria del trauma; b) en la recuperación de la memoria histórica como memoria compartida del dolor; c) en la teoría del trauma psicosocial, y d) desde la necesidad de atención psicosocial y de reparación. Este artículo no es, pues, ni debe ser considerado como el informe del peritaje, sino como un intento de analizar sus resultados en el marco de teorías ampliamente conocidas y de compararlos con los resultados de investigaciones sobre las consecuencias de la violencia política llevadas a cabo prioritariamente en América Latina.

\section{"De la locura a la esperanza". A modo de contexto}

El conflicto armado en El Salvador duró doce años y se adueñó de la vida y de los sueños de las salvadoreñas y los salvadoreños de bien, poblando su existencia de miedo, desconfianza y resentimiento cuyos 
ecos siguen todavía presentes. En términos metafóricos, siguiendo la estela de la cita de John Berger que preside este artículo, cabría decir que las víctimas todavía no han podido dormir. La violencia, dice la Comisión de la Verdad, fue una despiadada llamarada que avanzó por los campos de El Salvador arrasando aldeas, cercando los caminos y destruyendo vías de comunicación. Pero tuvo todavía un efecto mucho más devastador cuando penetró en las familias, golpeó los recintos sagrados y los centros educativos y "señaló como enemigo a quienquiera que no apareciera en la lista de amigos" (Naciones Unidas, 1993, p. 3) ${ }^{1}$. Esta arbitraria manera de definir a las personas fue la excusa perfecta para llevar a cabo una limpieza social en términos ideológicos, que se aproxima mucho a lo que la Asamblea General de las Naciones Unidas definiría como genocidio ${ }^{2}$ en su Resolución 96 del 11 de diciembre de 1946 a partir del juicio de Nüremberg contra algunos de los principales líderes del régimen nazi.

Aunque la dimensión real de la guerra está todavía lejos de ser conocida en toda su extensión y en todas sus dimensiones, distintas fuentes estiman en alrededor de 75,000 las víctimas del conflicto y más de 10,000 desaparecidos (Cruz, 1997). Conviene recordar a este respecto que el $60 \%$ del total de denuncias registradas por la Comisión de la Verdad $(22,000)$ tuvieron como protagonista (como perpetradora) a la Fuerza Armada, el $25 \%$ fueron imputadas a los miembros de los cuerpos de seguridad, el 20 \% recayó sobre los miembros de las escoltas militares, los siniestros Escuadrones de la Muerte fueron responsables del $10 \%$ de las denuncias y el FMLN lo fue del 5 \% (Naciones Unidas, 1993, p. 58).

Las negociaciones de paz concluyeron con los acuerdos de Chapultepec en enero de 1992 fruto de los cuales fue la creación de una Comisión de la Verdad cuyo Informe fue presentado en Nueva York en marzo de 1993. En dicho Informe, se fijan medidas conducentes al restablecimiento de la paz, la reconciliación nacional y a la reunificación de la sociedad salvadoreña a fin de "pasar de un universo de confrontación hacia otro de serena asimilación de cuanto ha ocurrido para desterrarlo de un porvenir signado por una nueva y solidaria relación de convivencia y tolerancia" (Naciones Unidas, 1993, p. 255). Ese tránsito solo es posible si se cumplen las dos siguientes condiciones: en primer lugar, la recuperación de la verdad, el "reconocimiento de lo que ocurrió" a fin sancionar a los responsables ("satisfacer los requerimientos de la justicia", dice textualmente la Comisión de la Verdad) y, en segundo lugar, "la reparación debida a las víctimas y a sus familiares" (p. 256). Desafortunadamente, estas recomendaciones no han podido llevarse a término

1 En el Epílogo, la Comisión de la Verdad (1993) abunda sobre esta infernal dinámica intergrupal en unos términos que conviene volver a reproducir porque no son pocos los indicios que apuntan a que esa dinámica sigue todavía vigente: "Sí, todo esto pasó entre nosotros, dicho en el lenguaje del Canto Maya. Cada uno había convertido su verdad personal en la verdad general. Toda bandera de partido o de grupo resultaba erigida en la bandera única, de acuerdo con el maniqueísmo que imperaba. Y cada lealtad, individual o partidista, se tenía como la sola lealtad. En aquellos tiempos, todos los salvadoreños en una u otra forma eran tan injustos con los demás salvadoreños, que el heroísmo de los unos se transmutaba de inmediato en maldición para los otros" (p. 258)

2 Ignacio Martín-Baró utiliza el término genocidio como título de un trabajo escrito hacia 1981 ("Genocidio en El Salvador") en el que da cuenta de lo que denominaba el "desbordamiento de la violencia". En ese artículo, defiende la necesidad de que el concepto de genocidio sea empleado también para definir el aniquilamiento sistemático y premeditado de personas no solo por su pertenencia étnica, racial o religiosa, sino en razón de su ideología, real o atribuida, como sería el caso de la matanza de El Mozote. El propósito de esta publicación es demostrar "que la Junta Militar Demócrata Cristiana está desarrollando e implementando prácticas genocidas en contra de la población civil salvadoreña" (Martín-Baró, 2016, p. 324). Sin referirse de manera directa al genocidio, la Comisión de la Verdad (Naciones Unidas, 1993) abunda en la idea de que los opositores políticos eran carne de exterminio: "las personas que postularan ideas contrarias a las oficiales, corrían el riesgo de ser eliminadas, como si fuesen enemigos armados en el campo de guerra" (p. 58). 
porque tan solo unos días después de la presentación del Informe de la Comisión de la Verdad fue decretada una Ley de Amnistía en nombre de la reconciliación nacional, impidiendo abrir juicios por los casos denunciados en el Informe. Hasta el presente, la mayoría de las víctimas no han sido reconocidas ni reparadas por el Estado, a pesar de que la Comisión recomendó establecer una política de reparación integral para una paz efectiva y una reconstrucción del tejido social salvadoreño.

En el transcurso de la guerra, se cometieron diversas masacres. Debido al número de víctimas, la perpetrada en El Mozote y en los cantones y caseríos de los alrededores es considerada como la más grande de las acontecidas en América Latina. El operativo de la Fuerza Armada, conocido como "Operación Rescate", se inició en Arambala el 10 de diciembre de 1981 y continuó su devastador recorrido por El Mozote, Ranchería, Jocote Amarillo, Los Toriles, La Joya y Cerro Pando, poblaciones todas ellas pertenecientes al departamento de Morazán, en el noreste de El Salvador, donde se cultivaban milpas, se hacían hamacas y artesanías con el mezcal y el metate. ${ }^{3}$ En el transcurso de tres días quemaron, asesinaron, violaron, destruyeron y arrasaron la zona convirtiendo en cenizas todo lo que encontraban a su paso. Muchos huyeron del horror desplazándose a otros lugares, dejando todo para salvar la vida. La Operación Rescate se saldó con la muerte de 1044 personas $^{4}$; el $49 \%$ de ellas eran niños y niñas menores de 12 años (509); el $6 \%$ eran adolescentes entre 13 y 17años (68); el $37 \%$, adultos entre 18 y 65 años (386: 202 mujeres y 182 hombres). No fue posible identificar la edad de 16 personas (2 \%). Las víctimas sobrevivientes fueron 373 .

En la masacre de El Mozote, perpetrada por el batallón Atlacatl, concurren dos importantes características. Forma parte, en primer lugar, de los llamados "conflictos de baja intensidad" en los que la guerra psicológica juega, muy probablemente, el papel más relevante. En segundo lugar, fue una acción claramente intencionada, bien planificada y llevada a cabo con un propósito exterminador. La Comisión de la Verdad (Naciones Unidas, 1993) lo ratifica en todos sus extremos: la matanza de El Mozote fue llevada a cabo "de manera deliberada y sistemática" (p. 164). Lo corrobora Leigh Binford en el que probablemente sea el más completo estudio sobre esta operación militar: no fue algo improvisado ni una reacción apresurada, sino una "operación planificada meticulosamente" a fin que quitarle al agua al pez, destruir el apoyo campesino a la guerrilla (Binford, 1997, p. 35), mediante acciones devastadoras destinadas a sembrar en la población un terror ejemplarizante y una inseguridad en todos los ámbitos de la existencia. De acuerdo con la Comisión de la Verdad, este sería uno de los patrones de la violencia perpetrada por los agentes del Estado y sus colaboradores. El objetivo, lo acabamos de señalar, consistía en desactivar el apoyo real, o supuesto, que se prestaba a la guerrilla o donde se sospechara una presencia activa de colaboradores. El Mozote, añade, "es una muestra lamentable de esta concepción que perduró durante algunos años" (p. 59). Es la misma táctica utilizada en las masacres perpetradas en Guatemala: acción en "zonas rojas", que se suponía actuaban como apoyo a la guerrilla y donde no había intereses económicos de los grupos dominantes, con el claro propósito de impedir la rearticulación comunitaria (el rebrote del apoyo a la guerrilla) empleando para ello la estrategia de tierra quemada y de vida destruida. El punto de partida es idéntico al de El Mozote: la base social de la guerrilla es toda la comunidad, de suerte que "en gran parte de las masacres, el objetivo era eliminar a toda la comunidad, independientemente de su edad y sexo" (Oficina de Derechos

3 Milpa: es la tierra destinada a cultivar maíz; mezcal: fibra de pita preparada para hacer cuerdas; metate: piedra de moler.

4 Ese universo de víctimas fue registrado por la asociación de víctimas. La sentencia ordenó hacer un nuevo registro de víctimas actualizado al Estado de El Salvador. 
Humanos del Arzobispado de Guatemala [ODHAG], 1998a, p. 32). Los enemigos son todos aquellos a los que no considero amigos. Ese fue, lo acabamos de ver, la consigna que presidió el conflicto armado.

En sus escritos sobre la guerra, MartínBaró presta atención a la guerra psicológica (ver, por ejemplo, Martín-Baró, 1998, pp. 231-236; 2003, pp.190-200), pero introduce un matiz histórico de interés. Desde su punto de vista, la guerra psicológica, que tiene como objetivo ganar la confianza de la población civil (ganar sus mentes y sus corazones, dice textualmente), a fin de que acepten las condiciones del orden social y del orden político imperante (Martín-Baró, 2003, p. 168), vendría a ser una estrategia posterior a la "guerra sucia" emprendida por el ejército entre 1980 y 1983. El operativo de El Mozote formaría parte, pues, de la guerra sucia. Y a juzgar por sus resultados, lo fue en toda la extensión de la palabra. La guerra psicológica vendría a ser su heredera a partir de 1983, a raíz de la llegada de Thomas Pickering como nuevo embajador de Estados Unidos a El Salvador. Una nueva estrategia del terror definida con un lenguaje algo más eufemístico.

\section{Memoria y verdad}

En algún otro momento (Yáñez, 2013), nos hemos hecho eco de la importancia de la memoria en el marco del trabajo con víctimas de la violación a los derechos humanos bajo una sencilla premisa: la recuperación de la memoria, condición para el restablecimiento de la verdad, es "el primer paso para la elaboración del daño sufrido" (p. 23). Teniendo en cuenta que el daño provocado por acciones como las perpetradas en El Mozote (y en general el causado por la violencia colectiva) afecta a un amplio grupo de personas, la memoria del dolor es, por definición, una memoria compartida, una memoria social, que permanece adherida a la vida de un determinado colectivo durante un largo periodo de tiempo. Esta es una evidencia no solo proveniente del trabajo de atención psicosocial con víctimas, sino de la propia teoría del trauma. La memoria no es solo una práctica social, ni tiene solo una dimensión histórica (Vázquez, 2002), sino que debe ser considerada como una práctica terapéutica con una dimensión psicosocial.

En los cuarenta años transcurridos desde que en 1980 la Asociación Psiquiátrica Norteamericana incorporara en el DSM-III el trastorno de estrés postraumático (TEPT) como una nueva categoría diagnóstica hasta la edición del polémico DSM-5 en 2013, se han venido produciendo diversas variaciones en la definición de sus características descriptivas, así como en los criterios para su diagnóstico. Sin embargo, hay un criterio que ha permanecido inalterable: el trastorno puede ser especialmente severo y persistente cuando el agente estresor es interpersonal $e$ intencional (American Psychiatric Association, 2013, p. 275). Este es el nexo de unión entre el trabajo de atención e intervención con víctimas y la teoría del trauma. De hecho, tanto en el DSM-IV como en el DSM-5, los acontecimientos que dan lugar a experiencias traumáticas susceptibles de desembocar en un trastorno tienen como marco de referencia común la violencia intencional (violencia sexual, secuestro, tortura, ataque terrorista, combates en el frente de guerra, etc.). Lo acontecido en El Mozote responde, pues, de manera cabal al primero de los criterios del TEPT (Criterio A): exposición a acciones bélicas como población civil a consecuencia de las cuales las personas sufren determinados síntomas (reexperimentación persistente del evento, evitación de estímulos asociados al acontecimiento traumático, alteraciones cognitivas y emocionales, etc.). No hay duda de que un evento como el que nos ocupa ha tenido, y sigue teniendo, todas estas secuelas, pero no son las únicas. A ellas se suma un daño social, una herida en los marcos de relación interpersonal, un deterioro de las redes primarias de protección y de apoyo (la familia y la comunidad) y un daño moral. En uno de sus artículos teóricamente más relevantes de toda su trayectoria intelectual "Guerra y salud mental", publicado en 1984 en esta misma revista, Martín-Baró (2003) 
no dudaba en afirmar que "el efecto más deletéreo de la guerra en la salud mental del pueblo salvadoreño hay que buscarlo en el socavamiento de las relaciones sociales, que es el andamiaje donde nos construimos como personas y como comunidad humana" (p. 343), y todavía más, cabría añadir, donde nos construimos como personas a partir de la comunidad. La experiencia traumática no se recluye en el interior de la persona, sino que se vuelca hacia el exterior dañando las relaciones interpersonales a través de la desconfianza y el miedo, deteriorando las relaciones intergrupales a través de la polarización, interrumpiendo la participación en actividades comunitarias a causa de la inseguridad, alterando la dinámica familiar a causa de la pérdida de alguno de sus miembros, debilitando la autonomía personal y desarticulando las relaciones al interior de las comunidades. Todas estas consecuencias forman parte del trauma psicosocial; son "la cristalización concreta en los individuos de unas relaciones sociales aberrantes y deshumanizadoras como las que prevalecen en situaciones de guerra civil" (Martín-Baró, 2003, p. 293), cuyo ejemplo más paradigmático son los acontecimientos de El Mozote. Una de las víctimas de la masacre de El Mozote lo define de manera muy sencilla: "uno, como ya vivió la guerra, uno se siente tímido y no hay confianza en las personas". En contextos de violencia colectiva como el que definió la realidad chilena bajo el régimen de Pinochet, "se desarrolla una percepción social de desconfianza básica, desamparo, pérdida de autonomía, o desesperación" (Lira y Castillo, 1991, p. 236). En una palabra, el TEPT tiene importantes limitaciones como única herramienta de trabajo. La más importante de ellas es la rígida categorización de los síntomas, su escasa sensibilidad hacia la diversidad de situaciones traumáticas, su generalizado desinterés por la etiología, un aspecto central en el trauma proveniente de esos eventos intencionalmente causados por la mano del ser humano, y su correspondiente desatención al entorno social y político en el que se enmarca el evento estresor. Todo ello sin olvidar que trauma no es sinónimo de trastorno.

La masacre tuvo, sin duda, un impacto psicológico-personal, que cada una de las víctimas ha vivido, experimentado y afrontado de manera particular; parte de esa experiencia es compartida entre quienes han estado expuestos al mismo evento. Al impacto personal se añade el deterioro de la vida social, en los términos que acabamos de señalar, y el daño moral. El primero de ellos causa un grave perjuicio a las relaciones interpersonales, a la vida en relación, de acuerdo con una feliz expresión utilizada por la jurisprudencia colombiana. Se trata de un perjuicio "que imposibilita a una persona para seguir relacionándose de manera normal con el mundo exterior, es decir, con las personas $y$ las cosas que la rodean, e impide ejercer las actividades rutinarias y placenteras, que, aunque no generen un beneficio económico, su privación deviene en una frustración existencial" (González, 2009, p. 36). Además, la violencia colectiva provoca una verdadera catástrofe social a través de las pérdidas familiares, del daño a los valores culturales significativos desde el punto de vista comunitario, a las propias estructuras y organizaciones comunitarias y a sus correspondientes redes de protección y de apoyo. El daño, la ofensa o el desprecio a los valores culturales, escasamente tenido en cuenta en la literatura sobre el trauma, ha sido definido como un daño moral.

Todas y cada una de estas heridas están presentes en los supervivientes de la masacre; todos estos daños persisten en la memoria de las víctimas, ratificando así uno de los supuestos del TEPT al que hemos aludido al comienzo de este epígrafe: en efecto, los acontecimientos traumáticos causados de manera intencional y premeditada por la mano del ser humano son especialmente severos y persistentes en el tiempo. Los expertos en el estudio de la memoria coinciden en esta apreciación: "la memoria de eventos emocionales, en general, y de sucesos emocionales negativos, en particular, suele 
ser especialmente precisa y significativamente más duradera que la memoria de los eventos rutinarios" (Ruiz-Vargas, 2010, p. 383). Es el "dolor imborrable de la ofensa" al que aluden algunos de los supervivientes de los campos de exterminio nazi, Primo Levi entre ellos. Esa ofensa ha quedado petrificada en la memoria de las víctimas, en su memoria personal y en su memoria colectiva. La memoria del dolor causado por la acción humana no es solo una memoria autobiográfica, sino una memoria compartida; tampoco es tan solo la memoria de hechos históricos pasados, sino el recuerdo vivo que han dejado en las personas que los protagonizaron o los sufrieron, como es el caso que nos ocupa. Esa es la diferencia que Halbwachs (2004) establece entre historia y memoria. Por mediación de esta última, el pasado se extiende hasta el momento presente, sobre todo, cabría añadir siguiendo a los especialistas en este campo, cuando ese pasado está repleto de eventos traumáticos. Además, la memoria colectiva se sitúa siempre dentro de un grupo, pertenece a un determinado colectivo en un determinado contexto $y$ en un momento concreto de su historia. Pertenece, más en concreto, al colectivo que estuvo implicado en determinados acontecimientos y "experimentó sus consecuencias" (p. 80), tal y como ocurre en el caso de la violencia colectiva en general $y$, de manera más particular, en el caso de El Mozote.

Lo que en este momento nos interesa de la memoria colectiva no es tanto volver a recordar sus fundamentos teóricos y sus distintas líneas de investigación, sino destacar dos de sus propiedades más valiosas de cara al objetivo de este artículo: su pertinencia como instrumento de intervención y su relación con la verdad de las víctimas. Respecto a la primera, ya dimos cuenta en su momento de la importancia del acompañamiento psicosocial como herramienta de apoyo psicosocial a víctimas de violaciones de los derechos humanos, como espacio facilitador del intercambio y elaboración de las experiencias traumáticas, de los procesos de recuperación de la autoimagen y la autoestima y de la reconstrucción de la dimensión social de las personas (Yañez, 2010, p. 51; Yáñez, 2013), vale decir, de su necesidad de relación y de lazos emocionales. No se nos puede ocultar que esa reconstrucción de la dimensión social guarda relación con la naturaleza de la salud mental como una "dimensión de las relaciones entre las personas y grupos más que como un estado individual" (Martín-Baró, 2003, p. 336). Es precisamente en el campo de la salud mental donde Mauricio Gaborit sitúa el valor de la memoria como un activo de cara a la intervención: "las grandes mayorías de las sociedades latinoamericanas, que poseen una historia larga de represión y guerra, tienen necesidad de acceder a esa memoria como paso indispensable para obtener siquiera un módico de salud mental e ir configurando su identidad personal y colectiva (Gaborit, 2006, p. 10).

La segunda de las propiedades de la memoria colectiva nos pone en contacto con el concepto de verdad. Lo hace a través de su potencial para conectar con la dolorosa realidad de las víctimas, para invitarnos a ser honestos con lo real, para dejarnos afectar por la tragedia y abrir con ello el camino hacia la solidaridad como premisa necesaria del "principio misericordia". Esta es la tesis sobre la que se acaba sustentando la propuesta teológica de Jon Sobrino: la realidad más real es la vida y, sobre todo, la muerte de los pobres, la "pobreza-muerte" (Sobrino, 1992), la violencia-muerte, diríamos en nuestro caso. $\mathrm{Si}$ para Jon Sobrino los pobres son "portadoras de verdad" (Sobrino, 2008, p. 106. Cursivas en el original), desde el punto de vista de la memoria colectiva, diríamos que las víctimas son asimismo portadoras de verdad. En ambos casos es idéntica la necesidad y el propósito de erradicar el sufrimiento, pasar de la teoría a la praxis (ver en más detalle la relación entre realidad y verdad en el artículo de este mismo número "Del impacto de la realidad como experiencia emocional al realismo crítico como posición epistemológica" y en Blanco y Gaborit, 2016, pp. 29-46). En último término, "la recuperación de la memoria histórica, como estrategia de salud mental para aquellos que han sufrido 
los efectos de la violencia, tiene como consecuencia la institucionalización de la verdad frente a lo que Martín-Baró llamó la institucionalización de la mentira" (Gaborit, 2006, p. 11).

El trabajo que aquí presentamos es la continuación de una línea de investigación e intervención desarrollada durante los últimos diez años (ver Yáñez, 2002; 2010; 2013). Esta línea ha tenido como objetivo desarrollar un marco conceptual y una metodología de trabajo para el apoyo psicosocial a víctimas de la violencia política en El Salvador. Ambos tienen como punto de partida la necesidad de recoger la memoria de las víctimas y como meta final dar pasos hacia la reparación del daño psicosocial que vienen arrastrando desde el conflicto. Es en este espacio donde se sitúa el trabajo que presentamos en este artículo. Su particularidad viene definida por el hecho de que las personas que han participado en la intervención son las víctimas de la mayor masacre cometida en El Salvador durante la guerra civil, la matanza de El Mozote.

\section{Metodología}

A pesar de que, como ya hemos comentado, este artículo no debe ser confundido con el informe del peritaje, creemos que es importante describir en detalle cuál fue la metodología empleada para la elaboración de dicho peritaje a cargo de la primera firmante del artículo llevado a cabo entre septiembre de 2010 y enero de 2012 en actividades mensuales.

\section{Participantes}

Aunque el número de víctimas registradas se elevaba a 398, las que participaron en el peritaje fueron 311. La identificación de la población se realizó sobre la base del listado de familiares sobrevivientes. Dada la magnitud de esta masacre, no fue posible incluir al universo total de víctimas; se tuvo acceso únicamente a una parte de las y los sobrevivientes y sus familiares, ya que el miedo a las represalias que aún persiste en esta población hizo que muchos no se atrevieran a declarar. Pero una vez que el presidente de la República, el 16 de enero del 2012 (tres meses antes de que el caso fuera a la Corte Interamericana) pidiera perdón a las víctimas en el marco del 20 aniversario de los Acuerdos de Paz en la misma plaza de El Mozote, se incrementó el número de personas que quisieron declarar.

\section{Objetivos}

Tres fueron los principales objetivos del peritaje:

1. Construir una metodología apoyada en datos fiables que permitiera hacer visible el rostro y escuchar la voz de las víctimas a partir de sus relatos sobre los hechos acaecidos durante la masacre.

2. En el contexto de la demanda presentada ante la Corte Interamericana de Derechos Humanos, se definió un segundo objetivo: conocer las experiencias que habían vivido, los daños que les habían sido ocasionados y sus expectativas de reparación.

3. El tercer objetivo iba dirigido a obtener información sobre el impacto común e identificar la posible existencia de un patrón compartido del daño causado por la masacre teniendo en cuenta: a) el "antes" de que acontecieran los hechos; b) el impacto de la masacre propiamente dicha; c) la falta de verdad y los efectos de la impunidad; d) el impacto del desplazamiento forzado, y e) expectativas del proceso y medidas de reparación.

\section{Procedimiento e instrumentos}

A fin de responder al primer objetivo se decidió utilizar una metodología mixta apoyada en métodos cualitativos y cuantitativos tradicionalmente empleados en investigaciones para el estudio del impacto de hechos de esta dimensión. 
En un primer momento, se procedió a la lectura y estudio del caso a partir de las demandas, el escrito de argumentos, las solicitudes y las pruebas de los representantes. Posteriormente, y a fin de responder al segundo objetivo, se informó a la comunidad sobre la realización de entrevistas individuales y sobre el trabajo en grupos. Se realizaron 311 entrevistas personales y familiares de dos horas de duración cada una. El guion de la entrevista se construyó sobre la base de varios instrumentos de referencia, principalmente de la Clinician-Administered PTSD Scale (Blake et al., 2000) y de la escala de depresión IPAT (Gómez et al., 2000). Para la validación de su contenido, se realizó en primer lugar una prueba piloto. Sus resultados sirvieron de guía para comprobar si el guion recogía todas dimensiones que se pretendía explorar. Todas las entrevistas fueron grabadas y transcritas a fin de recoger datos biográficos, para reflejar de la manera más precisa la riqueza de sus expresiones, los significados subjetivos atribuidos a cada una de sus experiencias y para poder prestar la máxima atención a los tonos de voz y a las pausas y los silencios que acompañaban los testimonios. El lenguaje verbal y no verbal era, pues, importante, como indicadores del estado emocional en que se encontraban las víctimas al hablar de la masacre. La trascripción de cada entrevista se integró a una base de datos. Se llevó a cabo un análisis de las entrevistas por medio del método de jueces, a fin de sistematizar los datos y poder establecer los principales hallazgos.

A fin de responder al tercer objetivo, se realizaron doce grupos focales (120 horas totales) con víctimas en cada uno de los lugares en los que ocurrió la masacre: $\mathrm{El}$ Mozote, Ranchería, Los Toriles, Jocote Amarillo, La Joya y Cerro Pando, con un promedio de doce personas por grupo, incorporando a desplazados de San Miguel, San Francisco Gotera, Arambala y Lourdes Colón. Además, se convocaron dos asambleas en las que participaron unas 300 personas y se realizaron nueve grupos focales para explorar las demandas en materia de reparación colectiva.
A tal efecto, se elaboró un instrumento-guía para los grupos focales a fin de recoger los patrones colectivos de daño y las expectativas en materia de reparación.

\section{Resultados}

Como es de esperar, los datos obtenidos con la ayuda de la metodología utilizada son muy amplios. En este apartado, nos vamos a limitar a ofrecer tan solo una muestra de ellos agrupados en torno a los siguientes testimonios: a) la vida antes de la masacre; b) el mapa del horror; c) la violencia contra las mujeres y los menores; d) el impacto sobre la comunidad; e) el desplazamiento forzado; f) impunidad, justicia y búsqueda de la verdad, y g) impacto personal sobre la salud. Estas son, de acuerdo con el peritaje, las experiencias traumáticas más comunes, las heridas más compartidas por las víctimas de El Mozote.

\section{La vida antes de la masacre}

En las investigaciones sobre la experiencia traumática apenas hay referencia y, por tanto, datos sobre la situación previa al hecho victimizante, como si la vida de las personas expuestas a cualquiera de las situaciones que definen el TEPT careciera de relevancia. De hecho, como hemos señalado en un epígrafe anterior, cuando la psiquiatría y la psicología clínica abordan el estudio de los eventos traumáticos, solo se preocupan de sus consecuencias, de las secuelas que siguen a la exposición, obviando el hecho, reconocido de manera unánime desde el DSM-III (lo hemos recordado en un epígrafe previo), de que el origen del evento tiene una especial repercusión en la duración e intensidad de sus secuelas, sobre todo, cabe añadir, cuando el acontecimiento traumático es inesperado y cuando la vida previa discurría en paz. Ese es el caso de la masacre de El Mozote.

La vida era feliz porque estaba rodeado de familia en donde todos nos juntamos $y$ platicamos. 
Yo me dedicaba a la agricultura. Era tranquilo. Testimonio de víctima

\section{El mapa del horror}

Sobrevivir a una masacre como la que tuvo lugar en El Mozote pone a las personas en una situación de extrema vulnerabilidad; se vive el horror, la impotencia, la carencia de control sobre la propia vida o la vida de los seres más queridos. Se siente como una situación extrema que marca un antes y un después, una ruptura con la propia existencia. En consonancia con el nombre del operativo (Tierra Arrasada), las personas describieron cómo fueron aniquilados sus seres queridos, sus bienes, el techo que los cobijaba, su milpa, sus animales, sus casas, sus objetos $y$ recuerdos, todo aquello que constituye un referente de vida y por cuya consecución se ha luchado con ahínco. Todo ello causa una herida profunda que socava el núcleo de la existencia misma al vivir un horror de dimensiones inimaginables.

Entonces fue cuando ya la Fuerza Armada empezó a acecharnos a nosotros. A nosotros si no nos salíamos nos iban a matar injustamente. Así mataron a la gente que no se fue a huir al monte. No se pudo defender y ahí la agarraron en sus casas y las mataron, porque mi mamá así fue, pues... La represión primero fue en las casas, miraban el ganado y lo mataban. Hallaban la gente y la mataban, y cuando no hallaban gente en las casas, le ponían fuego... Entonces con la quema de casas ahí terminó todo.

Hombre sobreviviente (La Joya)

El recuerdo del olor a carne quemada, tan parecido al que narran algunos de los supervivientes del Holocausto cuando quemaban los cuerpos recién salidos de las cámaras de gas, el humo negro que se extendió por los cantones, el ruido "como si estuviera explotando maicillo cuando se cocina" al referirse a los cuerpos pasto de las llamas, son imborrables. El montón de cadáveres tirados como animales, los huesos calcinados, todo eso constituye un mapa del horror que el ser humano no puede procesar. Hasta hoy les resulta inimaginable que alguien pueda hacer algo semejante y hasta hoy les resulta difícil poder narrarlo. Cuando contaban lo que vieron, lo que vivieron se quedaban mirando al infinito, callados, se les atragantaba la voz: "aún llevo el olor, el ruido quemándose, como si fuera ayer. El ser humano no puede con tanto horror. Inenarrable, inexplicable, insoportable", dice una de las víctimas.

\section{Las mujeres y las niñas y niños}

Los estudios sobre trauma coinciden en una mayor probabilidad de exposición en las mujeres y en las niñas y niños convertidos, así, en los dos principales grupos de riesgo. Se trata de uno de los acuerdos más sólidos en este campo de investigación, como tendremos oportunidad de ver en el epígrafe de la discusión. La matanza de El Mozote no fue una excepción. Siguiendo esta siniestra tradición, los soldados fueron especialmente despiadados con las mujeres durante la masacre. Fueron golpeadas, torturadas, violadas sexualmente, en muchas ocasiones frente a sus hijos o esposos. En definitiva, hubo con ellas un especial ensañamiento. A pesar del clima de confianza creado, los relatos fueron especialmente difíciles: se transmitieron a media voz.

Sí, yo fui violada dos veces por los militares. Me violó un guardia y me violó un soldado. El guardia me violó los primeros días que empezaron a maltratar a la gente. Estaba embarazada de mi hija la mayor y el soldado me violó. Me detuvo, me quitó los documentos y me dijo "pasa para allá". Yo iba con una niña grave para el hospital, porque yo me fui de aquí huyendo de ellos, y allá me llevó a un desvío, me quitó la niña y me violó.

Mujer sobreviviente (El Mozote) 
Hasta el presente se sabe de 509 niños y niñas menores 12 años víctimas de la masacre "con la idea de que no crecieran en una determinada ideología". Quitar el agua al pez, ese era, tal y como hemos apuntado, el objetivo de la operación. En este sentido, cabe señalar que en uno de los grupos focales se recordó que después de matar a unos niños en su casa, los soldados escribieron con sangre en la pared: "Un niño muerto, un guerrillero menos". Los niños y niñas de El Mozote, dijeron en ese grupo, esperaban la Navidad con la alegría de los juguetes, de los regalos, pero en su lugar recibieron balas y bombas. "Los niños andaban jugando en la plaza y esperaban la navidad y los juguetes, y lo que les vino fue la muerte. Tanto niño masacrado", dice una de las víctimas. Acabar con la infancia fue también un modo planeado de acabar con el futuro de la comunidad.

\section{El impacto sobre la comunidad}

La masacre disolvió la existencia de la comunidad y su identidad colectiva dejando un gran vacío social. La comunidad se reunía, celebraba sus rituales, mantenía sus redes afectivas y generaba un sentimiento de pertenencia integrando a todos los que formaban parte de ella. La plaza de El Mozote y las plazas de los caseríos aledaños eran lugares para la vida; los conventos e iglesias eran lugares para la oración y la reflexión donde se socializaba la vida en comunidad. La vida social se transformó en espacios de muerte y horror, crueldad, silencio. En el apartado 351 de la sentencia emitida el 25 de octubre de 2012 por parte de la Corte Interamericana de Derechos Humanos, de obligado cumplimiento por parte del Estado, se hace referencia al peritaje realizado por la primera firmante de este artículo en los siguiente términos: "Ahora bien, en lo que se refiere al impacto psicosocial y consecuencias emocionales sufridos por las víctimas, la perito explicó que la masacre disolvió las tramas sociales donde se insertaba el proyecto de vida tanto individual como comunitario". Muchos testimonios dan cuenta de cómo vivían en la comunidad antes de la masacre. La tranquilidad, la unión el clima de apoyo y colaboración que reinaba, con sus avatares normales en toda convivencia, quedó arrasado a partir de la masacre. "Para mí la comunidad fue rota definitivamente, porque unos tuvieron que huir y otros se unieron a la armada que había, unos salieron para un lado a refugiarse con sus hijos, o sea que se desorganizó de una manera la comunidad que quedo destruida", relata una de las víctimas.

\section{El desplazamiento forzado}

Los sobrevivientes debieron desplazarse forzosamente para salvar sus vidas. Una de las víctimas lo define de manera muy elocuente: "salimos como porque antes empezaron a matar los perros y mis padres dijeron vámonos de aquí, se va poner bien feo y hemos andado rodando de un lado a otro".

Este ha sido un tema muy presente en las narrativas: las situaciones de ruptura, especialmente la huida y la pérdida de todas sus pertenencias para salvar la vida. Una víctima relata que huyó con su hija de dos días de nacida hacia San Miguel, pero para poder integrarse al pueblo no mencionó que venía de El Mozote a fin de evitar que la estigmatizaran y vivir tranquila con su hija en el nuevo lugar. "Yo me dedicaba a la agricultura", dice otra de las víctimas. "Era tranquilo. Después fue todo distinto y salimos desplazados hacia Gotera 25 años, nos decían los refugiados".

Impunidad, justicia y búsqueda de la verdad

La impunidad quedó oficialmente confirmada con la Ley de Amnistía General para la Consolidación de la Paz aprobada el 20 de marzo de 1993 y ratificada recientemente (26 de febrero de 2020) por la Asamblea Nacional a través de la Ley Especial de Justicia Transicional, Reparación y Reconciliación Nacional (Ley de Reconciliación). El testimonio de una de las víctimas no puede ser más explícito al respecto: "No ha habido formas, medios, porque la amnistía era prácticamente olvidarse. Por ningún lado se 
ha podido hacer ninguna denuncia". Y si en algún momento alguien daba el paso, la respuesta era el silencio: "No se podía hacer. No nos oían", confiesa otra de las víctimas. Y añade: "Lo que ellos hacían eran ellos, pero que alguien de la gente iba a denunciar, no lo oían". Las instituciones no prestaron atención a sus demandas, a sus denuncias, a sus ruegos: "No hemos sido escuchados por las instituciones competentes". Los familiares han experimentado un alto grado de frustración y desesperanza ante la falta de respuesta de las autoridades a sus demandas, gestiones $y$ movilizaciones en San Salvador.

En los testimonios de los y las participantes, hemos encontrado un corpus narrativo claramente compartido y organizado alrededor del siguiente argumentario: a) la impunidad se ha amparado en la negación de los hechos, en el ensalzamiento de los victimarios por parte de las instituciones gubernamentales $y$ en el miedo por parte de las víctimas; b) eso ha conducido a una pérdida de confianza en las instituciones; c) la búsqueda, el descubrimiento y reconocimiento de la verdad de los hechos es el camino necesario para reclamar justicia y reparación, y d) para que ese camino lleve al fin deseado, no se puede recorrer de manera individual; necesita de participación y acción compartida y de organización comunitaria.

\section{El impacto personal sobre la salud}

Los impactos colectivos (el daño a la comunidad, el impacto sobre la familia) se acompañan de experiencias personales, aunque muy comunes, que remiten a la particular manera que cada una de las víctimas ha tenido de percibir, sentir y afrontar este acontecimiento tan traumático. Tal y como advertía el propio Martín-Baró en "Guerra y salud mental" al que nos hemos referido en páginas precedentes, no podemos negar el enraizamiento personal de este importante proceso psicológico $\mathrm{y}$, por tanto, tampoco podemos hacerlo cuando nos enfrentamos al estudio de la experiencia traumática. En la sentencia de la Corte Interamericana de
Derechos Humanos a la que hemos aludido anteriormente, en el apartado 351 se puede leer: "La perito advirtió que en general no han podido procesar el dolor por falta de espacios de validación social de su dolor, por la falta de apoyo institucional y colectivo. Es un dolor que se lleva muy dentro, en lo privado, paralizando muchos aspectos saludables, como dar o recibir afecto (...). Todo ello debe repararse en los planos individuales y colectivos".

\section{El deber de la memoria}

Durante tres décadas las víctimas fueron ignoradas y abandonadas y mantuvieron en silencio el horror vivido. El tiempo dedicado a escucharlas mediante las entrevistas en profundidad permitió compartir su dolor. Al sentir que su testimonio era escuchado y respetado desde la solidaridad y la empatía, se conformó un espacio de apoyo psicosocial. Esta no fue solo una experiencia individual. El trabajo con los grupos focales ayudó a la reconstrucción colectiva de su historia, al apoyo solidario cuando el relato se les atragantaba y no podían seguir hablando por la emoción que las invadía; ayudó igualmente a sentirse parte del proceso y generar sentimiento de pertenencia. Construir memoria es crear sentido, darle un significado compartido "mediante la comunicación y la acción conjunta" a un determinado evento del pasado (Vázquez, 2002, p. 1056). Así es como entre todas y todos pudieron relatar, dar testimonio y validar su experiencia colectiva. El poder sanador del grupo se volvió a poner de manifiesto. El empeño y la esperanza habían sobrevivido. Las víctimas y sobrevivientes habían mantenido viva la antorcha de la memoria en tiempos de oscuridad, y a raíz del proceso crearon una Asociación de Víctimas de la Masacre de El Mozote desde donde han seguido diciendo al mundo: "Ellos no han muerto, están con ustedes, con nosotros y con la humanidad entera". En la reparación y prevención de las secuelas es fundamental evitar la negación, juzgar a los culpables, y facilitar una recuperación de los daños 
sufridos. Hay que "condenar a los criminales para que la gente no se sienta culpable, hay que ayudar a las víctimas para que se liberen del dolor, la rabia, la culpa". La investigación realizada reconstruyó los hechos y sus memorias, sus padecimientos y sus experiencias traumáticas.

El resumen de los hechos relatados por las víctimas permite caracterizar el contexto político, social y psicosocial de la masacre. La percepción que las y los sobrevivientes tienen de los daños experimentados desde el punto de vista individual, familiar y comunitario se manifestó a través de sus testimonios y en el transcurso de los relatos recogidos en los grupos. Todo ello nos ofrece un panorama y un diagnóstico muy compartido sobre los hechos de la masacre, $y$, sobre todo, sobre sus sentimientos y emociones ante la política del olvido por parte de los poderes públicos.

1. Los hechos y sus consecuencias fueron silenciados por décadas. Con ocasión de este proceso, las personas comunicaron sentimientos de impotencia y de humillación y dieron a conocer su reclamo por la restitución de su dignidad y de su honorabilidad.

2. En sus relatos subrayaron la cobardía de los victimarios ante la indefensión de las víctimas, especialmente al matar a tantas mujeres y niños.

3. Destacaron la inocencia de las víctimas. Había un acuerdo unánime respecto a cualquier delito del que se les pudiera acusar, y sobre la necesidad de reclamar y responsabilizar a los militares.

4. Muchas de las víctimas señalaron que su experiencia era invisibilizada cuando se referían a los hechos de la masacre por mencionar únicamente lo acontecido en el caserío de El Mozote. Pidieron que se reconocieran a las víctimas de los lugares aledaños, recordando que fueron igualmente experiencias de horror, la falta de agua y comida entre otras, y enfrentando dificultades casi insuperables en la huida con niños y niñas en medio de una vulnerabilidad extrema.

5. Al referirse a los días previos a la masacre describieron el ambiente que se vivía en los caseríos. Contaron que los helicópteros sobrevolaban el lugar lanzando listas de nombres de personas que iban desapareciendo o asesinando. La gente suponía que los militares estaban instalados en la zona vigilando y cuidando la región, pero de un momento a otro se convirtieron en verdugos y asesinos.

6. Los testimonios se centraron en los hechos crueles y en las atrocidades, repitiéndolos una y otra vez y solicitando que se les creyera.

Los deseos y expectativas de cara al futuro en términos de reparación manifestadas de manera individual en las entrevistas, en los grupos focales y en los talleres psicosociales fueron consensuadas colectivamente en una asamblea de 300 personas. Las propuestas a este respecto fueron las siguientes:

1. Programa de desarrollo dirigido al caserío de El Mozote y lugares aledaños.

2. Creación de escuelas.

3. Indemnización compensatoria.

4. Investigación, juicio y sanción a todos los agentes del Estado que participaron en las masacres de El Mozote y lugares aledaños y en la obstaculización de las investigaciones.

5. Identificación de todas las víctimas de la masacre y sus familiares, y localización y entrega de los restos a las familias.

6. Reconocimiento público de responsabilidad por parte del Estado.

7. Creación de espacios de memoria para reconocer la dignidad de las víctimas y para recordarlas.

8. Producción y difusión de audiovisuales para la Memoria Histórica de los hechos. 
9. Designación del "Día Nacional de las Víctimas de Masacres cometidas en el Conflicto Armado de El Salvador".

10. Atención médica y psicosocial a las víctimas sobrevivientes y los familiares de las víctimas que sean identificados.

11. Proporcionar las condiciones necesarias para que las víctimas que aún se encuentran desplazadas puedan volver a su lugar de origen en condiciones seguras y dignas.

12. Eliminación de todos los homenajes para los autores de la masacre.

\section{Violencia política y trauma}

De acuerdo con los criterios del DSM-5 (American Psychiatric Association, 2013), no cabe duda de que las experiencias relatadas por las víctimas de El Mozote responden de manera íntegra al primero de los criterios del TEPT: exposición a un acontecimiento que pone en peligro su vida y las vidas de sus familias. El acontecimiento al que se vieron expuestas estas personas es la guerra, el primero de los eventos traumáticos contemplados en el DSM-5, en este caso en una condición especialmente vulnerable, la de personal civil. Se ha puesto también de manifiesto, tal y como reiteradamente han señalado las tres últimas ediciones del DSM, que los acontecimientos causados de manera intencional por la mano del ser humano son especialmente intensos y duraderos. En las víctimas de El Mozote se ha podido observar cómo cuarenta años después de la masacre sigue estando presente, de manera muy viva, la memoria del trauma. Según sus propias palabras "sufrieron una profunda herida": su vida personal, familiar y comunitaria quedó destruida. Los actos de crueldad comprendieron ejecuciones extrajudiciales, violaciones sexuales, uso de armas de fuego, uso de armas blancas, quema de víctimas, "como en un holocausto", para que no quedara huella ni rastro alguno. Aun hay lugares a los que la gente no se atreve a ir por miedo. No se permitió recoger y sepultar a los seres queridos, pisoteando así su dignidad y sus afectos. Si se veía a alguien recogiendo un cadáver era también objeto de persecución y muerte. Fue así como la gente se vio obligada a "tragarse" el dolor y no enterrar a sus muertos. Los que se atrevieron, lo hicieron de noche, con el pánico a sus espaldas y dejando una señal para reconocer el lugar donde había quedado la sepultura con la esperanza de poder enterrarlo posteriormente con dignidad. El dolor imborrable de la herida, el intenso daño moral se evidencia en varios testimonios.

En todos los relatos surgieron las "memorias congeladas" sobre la masacre. El recuerdo quedó detenido en ese día y ha permanecido vívido por décadas. Casi todas las víctimas manifestaron que recordaban cada día, con gran tristeza, la masacre. La memoria del trauma es especialmente dolorosa debido al poder que tiene para almacenar gran cantidad de detalles del evento, a su capacidad para mantenerlos durante años y de hacerlos presentes de manera intrusiva $y$ de manera constante a través de poderosos recuerdos somatosensoriales que nos trasladan al momento del evento. Este último es, de acuerdo con los expertos, el aspecto más dañino del trauma (Ruiz Vargas, 2010, p. 387). En el caso que nos ocupa, sus secuelas se han mantenido hasta el presente debido a la imposibilidad de procesar la experiencia y de elaborar las pérdidas a causa del poder de la memoria traumática, a la que Ruiz-Vargas (2005) señala como el enemigo interior, "un enemigo interior e íntimo, solo nuestro, silencioso, escondido en lo más recóndito de nuestro yo desde donde no para de atenazar nuestra conciencia" (p. 316). Un enemigo presente, uno tras otro, todos los días de la vida de las víctimas. De hecho, más de la mitad de las y los entrevistados declaró no poder aceptar la muerte de sus seres queridos experimentando con ello un duelo imposible que no les permite elaborar el daño.

Como hemos señalado en el primero de los epígrafes, las personas fueron tomadas por sorpresa, atrapadas y expuestas al terror hasta el agotamiento; muchas mujeres 
sufrieron violación sexual o daños físicos mientras otras personas eran forzadas a observar las atrocidades que se cometían; muchos sufrieron violencia extrema o fueron testigos de violencia extrema ejercida contra terceras personas. El $76 \%$ de las víctimas entrevistadas confesaron haber sufrido tortura psicológica al ser testigos de toda esa crueldad; observar lo que les ocurría a otros las dejó muy afectadas, impacto del que no se han recuperado. Ser testigo de eventos de tanta crueldad, que concluyen además con la muerte violenta de terceras personas, es uno de los criterios diagnósticos del TEPT (American Psychiatric Association, 2013, p. 274). Además de ello, las personas revelaron la presencia de diversos síntomas. El más común es la angustia expresada como dolor agudo hasta el punto de no poder hablar rompiendo en llanto, por momentos, al recordar los hechos traumáticos acompañado todo ello de dificultades de concentración y de retención de detalles sobre información reciente. Muchas de las víctimas dijeron que se sintieron intensamente heridos en el momento de los hechos, una herida profunda seguida de un intenso sentimiento de vulnerabilidad. Muchas de ellas sufrían síntomas depresivos y la mayoría confesaron dificultades para dormir, conciliar y mantener el sueño. El 80 \% seguía teniendo pesadillas sobre lo que ocurrió hace treinta años. El $55 \%$ describe síntomas de angustia y confiesa sentirse muy afectadas por la falta de justicia al sentir que los han tratado "como si fuéramos animales". Un 63 \% dijo presentar irritabilidad y tener explosiones de rabia. La mayoría reveló que vivía sobresaltada, como si fuera inminente otra masacre. En apartado 352 de la sentencia se cita de nuevo el informe de la perita: "se ha constatado que los daños sufridos por las víctimas se refieren no solo a partes de su identidad individual sino a la pérdida de sus raíces y vínculos comunitarios". El incuestionable impacto psicológico que tuvo la masacre para cada víctima en particular se vio acompanado de un impacto colectivo, que responde de manera muy precisa a los lineamientos teóricos del trauma psicosocial en los términos propuestos por Martín-Baró en el marco de la guerra civil de El Salvador (ver Martín-Baró, 2003, pp. 259-373) y en los planteamientos posteriores dirigidos a definir sus dimensiones y a analizar su presencia en contextos de violencia política (ver, entre otros, Blanco, Blanco y Díaz, 2016; Hernández y Blanco, 2005; Lira, 1999; Madariaga, 2002; MartínBeristáin, 1999; Portillo, 2000, por citar solo algunas de las propuestas desarrolladas en el marco latinoamericano).

El primero de los impactos nos encamina de nuevo hacia la memoria, en este caso hacia la memoria colectiva. Pennebaker ha establecido un nexo entre memoria colectiva y trauma bajo un argumento cuya verosimilitud ha quedado claramente de manifiesto en los resultados del informe pericial: "los sucesos que representan o producen cambios significativos a largo plazo en las vidas de las personas, llevarán a memorias colectivas más duraderas" (Pennebaker y Crow, 2000, p. 253). En consonancia con lo acontecido con las víctimas de El Mozote, lo que estos autores predicen es que el silencio oficial, la negación de los hechos, la represión de la narrativa del trauma no provoca olvido, sino una consolidación de las memorias colectivas asociadas al evento traumático. Por otra parte, y mirando directamente a la intervención, está bien asentada la idea de que una de las estrategias de afrontamiento del trauma pasa en poder hablar, comunicar, compartir las experiencias vividas. Cuando en 1989, el propio James Pennebaker, a partir de un experimento de laboratorio, mostró que en las personas que podían compartir sus experiencias se reducía la presión arterial y la tensión muscular, puso la primera piedra de algo que en la actualidad es un hecho consolidado: compartir las experiencias traumáticas redunda en beneficio tanto de la salud física como de la mental (Pennebaker, 2003). La memoria colectiva juega, así, un importante papel en la supervivencia supraindividual (Leone, 2000, p. 153), vale decir, en la supervivencia de aquellos colectivos que han estado expuestos a una experiencia 
traumática común. Por otra parte, desde los planteamientos terapéuticos grupales, es bien conocido el poder que tiene el grupo para favorecer la expresión de sentimientos de pena, dolor, miedo, angustia, para reparar vínculos quebrados y desarrollar lazos de confianza, empatía y apoyo, de ayudar para el afrontamiento de las crisis de identidad, etc. El poder sanador del grupo se pudo observar en el transcurso de dos seminarios celebrados en Santiago de Chile y en Asunción en 1991 y 1992 con la participación de profesionales de salud mental que trabajaban con víctimas de violación de Derechos Humanos (ILAS, 1994. Gloria de Pila y José Luis Henríquez participaron en esos seminarios como representantes de El Salvador). Todo ello ha sido observado también en los procesos de atención psicosocial llevados a cabo con víctimas de la guerra en El Salvador: el grupo infunde esperanza, ofrece guía, consejo, hace sugerencias, es una fuente de información, comparte experiencias, propone soluciones, ayuda a descubrir aspectos positivos en cada una de las personas; es una escuela de convivencia, de empatía, de respeto, de tolerancia y un escenario privilegiado de aprendizaje (Yáñez, 2013, p. 91-92). Este es un hecho bien conocido, aunque bastante olvidado, desde los National Training Laboratories iniciados en Estados Unidos en 1947 a la sombra de las enseñanzas e investigaciones de Kurt Lewin en su Centro de Dinámica de Grupos. Los expertos en terapia grupal nos han ofrecido buena prueba de ello (Peñarrubia, 2014).

El segundo de los impactos nos remite a colectivos que sufrieron de manera particular las atrocidades de los soldados del batallón Atlacatl: las mujeres y las niñas y niños. Este es un hecho muy común en los escenarios bélicos. El Mozote no fue una excepción. Leigh Binford lo describe ratificando así una parte importante de los testimonios recogidos en el informe pericial: "cerca del mediodía, las tropas del Atlacatl llegaron a la casa de Alfredo Márquez, escogieron a las muchachas mayores y a las mujeres jóvenes y las obligaron a subir las faldas boscosas de los cerros de La Cruz y El Chingo, donde las violaron repetidamente en el curso de las siguientes doce o dieciocho horas y luego las asesinaron" (Binford, 1997, p. 43).

Los ataques a la maternidad se manifestaron en los descuartizamientos desde el vientre y los senos. Los senos eran cortados, segados. Golpearon a las mujeres en el abdomen, con palos y con la punta del fusil atacando el recipiente de la vida. Ante la orden de no dejar ni una semilla, se intentó acabar con la semilla de vida. Muchas mujeres fueron empaladas; las abrían introducido un palo desde la vagina o abriendo sus vientres si estaban embarazadas. La guerra se prolongaba en el cuerpo de la mujer convertido en símbolo de negación de la reproducción. Se prolongaba también en la humillación a sus hombres por no poder protegerlas $y$ defenderlas de la que es una de las afrentas que forman parte del dolor imborrable de la ofensa y del daño moral. Buscaron destruir el círculo afectivo más decisivo en la vida de una persona: la familia. Con ello aniquilaron el escenario que da respuesta a las principales necesidades psicológicas de apego, identidad, protección, apoyo, pertenencia y, de paso, truncaron numerosos proyectos de vida. Algunas mujeres sobrevivientes estaban embarazadas o con niños de pecho. La angustia y el miedo que padecieron en aquel momento, junto con el hambre y con la sed, creen que están en la base de las dificultades de aprendizaje o los trastornos que tuvieron sus hijos después. La masacre prolonga sus efectos hasta el presente a través de los hijos e hijas de los supervivientes.

Las relaciones entre experiencia traumática y género son bien conocidas en el marco de la investigación (ver a este respecto las revisiones epidemiológicas de Norris, Foster y Weissharr, 2002; Norris, Friedman, Watson, Byrne, Díaz y Kaniasty, 2002; Norris y Sloane, 2007). En el artículo de este mismo número dedicado al maltrato infantil ("El maltrato infantil en $\mathrm{El}$ Salvador: la calle como huida y la pandilla como refugio"), hemos podido observar que la mayor vulnerabilidad de las mujeres, incluida la violencia sexual, da comienzo 
ya en el entorno familiar. En el caso de la guerra, las investigaciones de Vázquez, Ibáñez y Murguialday (1996) muestran que muchas de las mujeres que militaron en las filas del FMNL, como de las que permanecieron como civiles, "han sido víctimas de traumatización extrema y sufren actualmente las secuelas de los duelos no elaborados por las pérdidas de sus familiares, por las violaciones sufridas y por la desesperación de haber vivido tanto sufrimiento" (p. 246). El Informe de la Comisión de la Verdad de Guatemala dedica una atención especial a la violencia contra las mujeres (ODHAG, 1998b, pp. 203-237). Las actuaciones de los cuerpos represivos incluían "formas de violencia específica" y especialmente despiadadas contra la mujer: separación de sus hijos, violaciones particulares y violaciones masivas, extracción violenta del feto a las embarazadas, cocinar y bailar para los victimarios, etc. "En el interminable listado de vejaciones, humillaciones y torturas que las mujeres padecieron, la violación sexual ocupa un lugar destacado, por ser uno de los hechos crueles más frecuentes y que reúne unos significados más complejos en cuanto a lo que representa como demostración de poder para el victimario, y de abuso y humillación para quien la sufre" (ODHAG, 1998, p. 210). A consecuencia de todos estos actos, alrededor del $60 \%$ de las mujeres han quedado psicológicamente afectadas (p. 218). A su través quedan truncados los proyectos familiares, el cuidado y el sostén afectivo dentro del hogar y acabaron por descomponerse los vínculos con el núcleo familiar (hermanos y hermanas). A todo ello hay que añadir los impactos y los daños personales, sobre todo cuando de por medio ha habido una violación, algo extraordinariamente frecuente en situaciones de violencia política.

El Informe sobre la represión política en Guatemala dedica también un capítulo a la violencia contra la infancia. Lo titula, de manera muy oportuna, "La destrucción de la semilla". Tampoco en El Mozote se libraron de esta plaga. Rufina Amaya recuerda cómo los soldados asesinaron a "varios centenares" de niños y niñas que se habían refugiado en una casa. Durante los asesinatos se escucharon gritos de los menores pidiendo auxilio; después, los soldados prendieron fuego a la casa (Binford, 1997, p. 44-45). Tanto en un caso como en otro (Guatemala y El Salvador), la violencia contra los menores tiene el propósito declarado de cortar de raíz la subversión, segar la posibilidad de su continuidad. "El camino se llenaba de cabecitas de niños y niñas rodando. De mujeres con los pechos colgando, o los vientres abiertos, de cuerpos calcinados", dice una de las víctimas. En el caso de Guatemala, "el plan del Ejército era dejar sin semillas. Aunque sea un patojito de un año, de dos años, todos son malas semillas, así cuenta. Así es su plan del Ejército. Eso es lo que yo he visto", relata una víctima (ODHAG, 1998b, p. 81). En muchos casos, el ensañamiento contra las niñas y los niños es empleado como una forma de quebrar a los adultos y provocar su colaboración (p. 85). Eso intensifica todavía más el daño, supone un tormento añadido convirtiendo el impacto en algo difícil de superar.

Martín-Baró (2003, pp. 295-310) dedicó algunos de sus trabajos a analizar las consecuencias de la guerra en la infancia. También lo hizo José Luis Henríquez dentro del mismo contexto (Henríquez, 1992) y Florentino Moreno (1991) en el marco centroamericano. En todos los casos, se alude a la posibilidad de que, con el paso del tiempo, hagan acto de presencia trastornos ocasionados por la guerra en forma de terrores nocturnos ("fantasías sobre mundos lúgubres dominados por el enemigo", dice Florentino Moreno), deterioro de la capacidad de atención, conductas regresivas, insensibilidad emocional, todo ello, apunta Henríquez (1992) de acuerdo con la experiencia que se haya tenido en el marco del conflicto. Teniendo en cuenta que en el caso de El Mozote esa experiencia ha sido directa y extraordinariamente inhumana, todas estas consecuencias son altamente previsibles. Hay, finalmente, un secuela de la guerra para los menores que tiene un especial alcance social: el aprendizaje de la violencia "como la respuesta más importante para resolver los problemas de la existencia" 
(Martín-Baró, 2003, p. 301) con el consiguiente deterioro de la vida social, añade, y la insensibilidad ante sus efectos, que forma parte de la cultura de la violencia que todavía perdura en El Salvador (ver número monográfico de ECA, 1997, 588).

Tanto la violencia contra la mujer como contra la niñez forman de la destrucción familiar y comunitaria. Esta es una de las dimensiones del trauma psicosocial (Blanco, Blanco y Díaz, 2016) que ataca de manera directa a una de las fuentes más importantes de protección y de apoyo psicosocial con la que cuentan las personas. La masacre de $\mathrm{El}$ Mozote forma parte de esta estrategia con la estudiada intención de llevar a la población civil un mensaje aleccionador de la suerte que podía correr colaborar con la guerrilla o, simplemente, ser percibidos como cómplices. El horror perpetrado en El Mozote da cuenta de cómo se quiso acabar con la zona, con su gente: vaciar el territorio y expulsarlos. Mucha gente huyó; otros se escondieron en cuevas o en lugares en los que se sentían protegidos y relatan las estrategias de las que se valieron para evitar ser masacrados "monteando", viviendo al aire libre y escondiéndose en cualquier parte. La desaparición de la gente que vivía en El Mozote y sus lugares aledaños significó la disolución de las tramas sociales y culturales, de los proyectos de vida y de las relaciones donde la vida adquiría sentido. Esos nexos sociales y redes afectivas dejaron de existir; ese vacío ha sido percibido como "denso y triste" de tal suerte que les gustaría que la comunidad volviera a revivir la comunidad y resignificarla para los jóvenes, para que "se vuelva a la vida".

La masacre afectó al entramado social y simbólico de la comunidad. Se destruyeron casas y objetos significativos, robaron y mataron animales: "me llevaron las vacas, las gallinas", "se llevaron mis vacas, mataron a dos toros". Para el universo campesino, estas pérdidas tenían no solo significación material, sino afectiva. Además, quedaron desarticuladas las formas de organización, los liderazgos, las estructuras organizativas y las cooperativas que los unían en sus proyectos de desarrollo. Toda forma de organización quedó asociada a la muerte. La misma palabra quedó estigmatizada, ya que para el Gobierno y para los militares, en su delirio fratricida, evocaba el fantasma revolucionario. Fue una lógica de exterminio total, una destrucción completa de los espacios sociales, que los sumió en un hondo dolor no solo por haber perdido a sus seres queridos, sino por sentir cómo había quedado aniquilada la vida comunitaria. No era solo una pérdida; era una humillación, una quiebra de los proyectos de vida y una ofensa a su dignidad colectiva. Una herida moral, en una palabra. Una masacre irrumpe en lo personal, en lo familiar y lo comunitario al destrozar las vidas, pero también la base de la confianza social y del apoyo mutuo. Hubo divisiones entre familias al pensar que alguien "les había puesto el dedo" (los había denunciado). Al no disponer de una explicación racional del operativo se creó un clima de desconfianza tal que no se sabía quién era el denunciante.

La práctica totalidad de los Informes de las distintas Comisiones de la Verdad realizados en aquellos países de América Latina que han sufrido el azote de la violencia política aluden a la destrucción familiar y comunitaria como una de las secuelas más visibles y respecto a cuyas consecuencias existe un acuerdo compartido. Cuando condenan a una persona, dice la Comisión chilena, cuando la encarcelan, la torturan, la desaparecen o la asesinan, condenan a toda la familia, ya que se produce un daño en las redes y vínculos afectivos familiares "con las consiguientes consecuencias de mayor soledad, aislamiento y sensación de pérdida y abandono" (Corporación Nacional de Reparación y Conciliación, 1996, p. 1150). Algo muy parecido observamos en el informe de la Comisión Nacional sobre la Desaparición de Personas (CONADEP) en Argentina: la desaparición de una persona afecta de manera directa a la estructura y la estabilidad del núcleo familiar y quiebra una de sus principales funciones: la satisfacción de necesidades emocionales de pertenencia, 
identidad, apoyo, etc. (CONADEP, 1985). Donde de una manera especialmente patente quedan detalladas las heridas tanto a la familia como a la comunidad es, de nuevo, en el Informe sobre la represión política llevada a cabo en Guatemala. En el caso de la familia, se reitera la desintegración familiar como una de las consecuencias más dañinas, ya que la "pérdida de los seres queridos implicó un cambio brutal en la vida de la familia, que ha estado marcada por un antes y un después de los hechos" (ODHAG, 1998, p. 73). A ello se añade el cambio en la estructura y los roles familiares, dificultades económicas, graves dificultades para la reconstrucción de la vida familiar, bloqueo en el desarrollo $y$ proyecto de vida de la familia. Por lo que respecta a la comunidad, este informe ha sido el que con más precisión ha mostrado los efectos de la violencia sobre su dinámica a lo que, muy probablemente no sea ajena la estructura social guatemalteca, tan apegada a estos escenarios. Se han producido pérdidas materiales y simbólicas (el daño a la naturaleza, por ejemplo, es una de ellas), se han dañado componentes y piezas que forman parte de la cultura y de la vida social (por ejemplo, la profanación de lugares sagrados, envenenamiento del agua, quema de iglesias, etc.), se ha destruido el tejido social a través del asesinato de líderes y ancianos; se ha dividido a las comunidades en términos de "buenos" y "malos", "amigos" y "enemigos"; se ha roto la cotidianeidad por medio de la limitación de actividades ligadas a la dinámica comunitaria; se han quebrado las redes de apoyo social entre las familias y vecinos; se ha dañado la identidad social por medio del ataque a ritos y celebraciones comunitarias o la prohibición del uso de ropa tradicional: "muchas mujeres tuvieron que cambiar su traje o dejar su ropa tradicional como una forma de ocultar su identidad. De la misma manera, muchos hombres tuvieron que ocultar su origen para no ser acusados de guerrilleros" (ODHAG, 1998, p. 130). La necesidad de ocultar la identidad forma parte del daño moral, presente en la mayoría de las heridas causadas a la comunidad a través de las ofensas a los valores culturales, al idioma, a los trajes tradicionales, de la burla a los ritos y tradiciones populares, a las normas de funcionamiento comunitario, del desprecio a creencias ancestrales que forman parte de esas asunciones fundamentales que, según las teorías cognitivas, quedan afectadas a raíz de la experiencia traumática (Janoff-Bulman, 1992). Esta es una herida presente en la práctica totalidad de los escenarios bélicos.

En alguna medida, el desplazamiento forzado por la masacre puede ser considerado como parte de la destrucción comunitaria. En el caso de las víctimas de El Mozote, el desplazamiento generó inseguridades, temor, sentimiento de indefensión $e$ incertidumbre sobre el futuro. Un $12 \%$ de los sobrevivientes se desplazaron hacia Honduras; un 86 \% San Salvador. A Guatemala y EE. UU. se desplazó el $1 \%$, respectivamente, y a Nicaragua un 2 \%. El regreso se inició en 1991 y se prolongó hasta 2009. En ese periodo volvieron algo más del $45 \%$.

Al daño contribuye también, en una medida nada despreciable, la impunidad. La persistencia de la impunidad a través de mecanismos jurídico-políticos adquiere dos modalidades. En la primera de ellas, el discurso político reproducía la negación social de lo ocurrido: era necesario desde el punto de vista psicológico para las víctimas y desde el punto de vista social "pasar a otra cosa", "no abrir heridas", "pasar la página", se argumentaba. Esa estrategia ha conseguido que el $99 \%$ exprese un profundo malestar cuando lo que se cuenta no se corresponde con lo sucedido. Resulta sorprendente que, después de más de treinta años, los testimonios de las víctimas de la masacre de El Mozote sean desconocidos no solo para las nuevas generaciones, sino para los que vivieron ese período de la historia. La segunda razón sobre la que se instala la impunidad es la reproducción del discurso político que ha culpabilizado a las víctimas tergiversando la realidad de los hechos. Si las víctimas eran las culpables, las autoridades cumplieron con su deber en un contexto de guerra. Ese discurso exculpa 
públicamente a la fuerza pública. La inversión de la culpabilidad contradice la experiencia de las víctimas y pretende erosionar su juicio de realidad.

Los hechos fueron negados. La crueldad de la masacre, la evidencia del horror se ocultó con versiones distintas acusando a las víctimas de mentir. La falta de una verdad oficial e institucional y el no reconocimiento de los hechos agravaron considerablemente el daño. Por si fuera poco, la negación de los hechos no solo estuvo acompañada de la falta de voluntad política para hacer justicia, sino por el ensalzamiento y el homenaje a los victimarios, especialmente a quien había sido el cerebro y cabecilla de la masacre, el coronel Domingo Monterrosa, sobre todo después de su muerte en 1984 a raíz de un ataque de la guerrilla al helicóptero en el que viajaba. El homenaje a los victimarios supone un verdadero calvario para las víctimas porque es percibido como un desprecio a su dolor, lo que, en el fondo, es sentido por ellas como un desprecio a sus personas. En este caso, al olvido se une la ausencia de arrepentimiento y un doble mensaje, el de que volverían a hacer lo mismo, y el de que olviden toda posibilidad de justicia.

Para buscar la verdad de lo sucedido, cientos de sobrevivientes se fueron a escarbar la tierra para "escarbar" la verdad. El $66 \%$ saben dónde quedaron sus seres queridos, aunque el $59 \%$ no pudo enterrarlos dignamente; el $34 \%$ restante no sabe dónde están los restos de sus familiares. A petición de ellos, tiempo después de la masacre, se hicieron exhumaciones en condiciones difíciles. Al preguntarles por los motivos, un $22 \%$ dijo que lo hicieron para poder elaborar el duelo, el $43 \%$ a fin de tener pruebas para alcanzar la verdad y buscar justicia, el $33 \%$ afirmó que buscaban la cohesión de la comunidad, realizar entierros colectivos y finalmente lograr un reconocimiento de los hechos. La mayoría señaló que el miedo les impidió hacer el duelo.

Aunque con mucho más recorrido jurídico que psicológico, la impunidad forma parte de la naturaleza psicosocial de la experiencia traumática: "la impunidad no es solo, entonces, una situación jurídico-política. Tiene profundos efectos psicosociales" (Yáñez, 2013, pp. 36). En el caso de El Mozote, el desamparo de la víctima ha sido la tónica en los últimos cuarenta años y ha sido, por tanto, lo que ha desencadenado la denuncia a la Corte Interamericana de Derechos Humanos y la puesta en marcha del peritaje. El Informe de la Comisión de la Verdad ya lo advertía: El Salvador dispone de un débil sistema de justicia "y una tradición de impunidad por abusos cometidos por oficiales y miembros de las familias más poderosas" (Naciones Unidas, 1993, p. 182). La impunidad forma parte del trauma psicosocial a través del "desvanecimiento de la memoria" y del poder del olvido (Delgado, 2000, p. 2) con el que los victimarios y sus ideólogos y promotores intentan seguir alimentando la mentira institucionalizada y ocultando la verdad, y ello siempre juega a favor de la impunidad: "conocer la verdad, fortalecer y templar las voluntades para encontrarla; ponerles fin a la impunidad y al encubrimiento...; tales son las secuelas creativas después del acceso analítico a la verdad". Ese era el propósito de los trabajos de la Comisión (Naciones Unidas, 1993, p. 4). En el caso de El Salvador, como en otros tantos, el cumplimiento de ese objetivo se ha visto impedido por los "olvidos patrióticos", por estrategias ideológicas (trampas, para entendernos) que invitan "a no analizar aquello que permanece abierto, a dejar el pasado, o, por lo menos algunos de sus episodios más dramáticos, sin tocar" (Dobles, 2009, p. 180). La impunidad no solo acentúa el daño y hurga de manera deshonesta en la herida e incrementa el sufrimiento de las víctimas, sino que provoca nuevos daños.

Al prevalecer públicamente las versiones oficiales exculpatorias acusando a las propias víctimas de ser las responsables de la masacre, sumado a la impunidad sostenida por décadas, el sufrimiento se agrava. La tergiversación de la verdad y el intento de reinterpretar los hechos afecta también a su juicio de realidad creando una desconfianza 
no solo con las instituciones, sino respecto de las creencias básicas sobre el mundo reiteradamente analizadas desde las teorías cognitivas sobre el trauma (Janoff-Bulman, 1992; Foa et al., 1998). La percepción de que no hay justicia en el mundo les resultaba incomprensible. Llevándolo a un plano más personal, la pregunta constante era: "¿por qué a mí?". Pero también percibían que había quienes "sabían" y no querían decir, aumentando con ello su desconfianza y sufrimiento. La negación oficial de la verdad, según dijeron, los llevó a imaginar toda suerte de horrores.

Contra la impunidad, justicia y reparación. En el apartado 325 de la sentencia de la Corte Interamericana de Derechos Humanos, se cita una parte del peritaje: "Habiendo constatado las violaciones y los daños sufridos por las víctimas, tal como lo ha hecho en otros casos, la Corte considera necesario ordenar medidas de rehabilitación en el presente caso. Al respecto, estima que una atención integral a los padecimientos físicos, psíquicos y psicosociales sufridos por las víctimas en el presente caso resulta ser la reparación idónea. En efecto, dado las características del presente caso, la Corte estima que la asistencia psicosocial es un componente reparador esencial". La Comisión de la Verdad identificó dos niveles de reparación. El primero de ellos, material. A él, lo hemos visto en un epígrafe anterior, han aludido de manera reiterada las víctimas. $\mathrm{El}$ segundo, especialmente pertinente desde las premisas de la psicología, es una reparación moral que tiene en "el reconocimiento de la honorabilidad de las víctimas y de los graves delitos de los que fueron víctimas" su principal cometido (Naciones Unidas, 1993, p. 257). Recientemente, el Journal of Traumatic Stress ha dedicado un número monográfico al daño moral. Lo ha hecho desde una perspectiva muy sesgada hacia el ámbito militar, como si solo fuera este colectivo el que ha sufrido daños morales. La definición propuesta (ver
Griffin et al., 2019, p. 359) 5 no añade nada nuevo al planteamiento que acabamos de mostrar, y a lo largo de todo el monográfico se pone de manifiesto, una vez más, el desconocimiento que la tradición clínica de factura norteamericana tiene de lo que acontece fuera de sus fronteras.

Se ha podido observar cómo sus precarias condiciones de vida, el abandono institucional, la persistencia de las amenazas, la inseguridad y el miedo han impedido por años afrontar ese proceso. Ha sido precisamente la falta de reconocimiento del Estado, la falta de apoyo, de validación social y de respuesta estatal para hacer efectivos sus derechos de verdad, justicia y reparación la que ha alentado a las víctimas a presentar su caso ante la Corte Interamericana. "No había apoyo. Todos tenían miedo", relata una víctima. "Y la verdad de nosotros", puntualiza otra, "nadie quiere escucharla... no se escuchaban nuestras voces, no se escuchaban, este... no hallábamos a quien recurrir, o sea, mi mamá y más que anduve en muchas partes y quién, nadie, hasta hoy".

En este sentido, uno de los datos que responde de manera más firme a la perspectiva psicosocial del trauma es la convicción de que el camino abierto a la justicia y a la reparación ha sido posible gracias, en primer lugar, a la ayuda y colaboración desinteresada de determinadas personas $e$ instituciones $y$, sobre todo, a la convicción de que este es un camino que hay que recorrer de manera conjunta, compartida, hombro con hombro desde el apoyo y la confianza mutua en la consecución de una meta necesaria y beneficiosa no solo para el colectivo de víctimas, sino para la sociedad en su totalidad, que no es posible conseguirla cada uno y cada una por su cuenta. "Una sola golondrina no hace verano", se pudo escuchar en uno de los testimonios; "una sola abeja no hace panal",

5 La definición se sustenta sobre dos supuestos: a) posibilidad de el victimario sea capaz de evaluar la violación de una infracción moral que acarrea consecuencias para la víctima, y b) posibilidad de que las personas sientan que son víctimas de una conducta transgresora conducente a problemas "betrayal-based". Una concepción muy estrecha del daño moral que contrasta con la que se ha elaborado desde los escenarios y las experiencias de la violencia política. 
dice otra víctima. Para ello los testimonios coinciden en un aspecto metodológicamente imprescindible: la necesidad de organización, un término tabú para los poderes públicos, como hemos comentado en páginas anteriores.

Al final del recorrido, las palabras de John Berger que presiden este artículo han empezado a encontrar sentido: estamos en el camino de reemplazar la oscuridad por la confianza. A la psicología le espanta el oscuro reverso de la guerra, un acontecimiento que si deja algo tras de sí son precisamente sombras. $\mathrm{Su}$ objetivo es precisamente adentrarnos en la oscuridad, describirla con detalle y seguir sus huellas hasta encontrar la luz. Esa ha sido y seguirá siendo nuestra meta. Los procesos son ciertamente largos, pero tienen sentido cuando las víctimas toman la palabra desde su dignidad y, en su búsqueda de la verdad, transforman el dolor en acción y resistencia manteniendo viva la llama de la memoria. En definitiva, se hace necesario recuperar la memoria y la verdad de lo sucedido, "porque las víctimas durante mucho tiempo no han podido señalar a los culpables y necesitan un reconocimiento social de su sufrimiento $y$ de las injusticias que vivieron. Les hace falta poder compartir sus experiencias para recuperar la dignidad que les fue arrebatada" (Yáñez, 2002, p. 1119).

\section{Referencias bibliográficas}

American Psychiatric Association. (2013). Diagnostic and statistical manual of mental disorders (5th ed.). APA.

Berger, J. (2009) De A para X. Una historia en cartas. Alfaguara.

Binford, L. (1997). El Mozote. Vidas y memorias. UCA Editores.

Blake, D., Weathers, F., Nagy, L., Kaloupek, D., Klauminzer, G., Charney, D., Keane, T. \& Buckley, T. (2000). ClinicianAdministered PTSD Scale (CAPS). National Center for PTSD.
Blanco, A. y Gaborit, M. (2016). La racionalidad inmanente a la psicología como ciencia y como profesión. En I. Martín-Baró. El realismo crítico. Fundamentos y aplicaciones (pp. 3-75). UCA Editores.

Blanco, A., Blanco, R. \& Díaz, D. (2016). Social Dis(order) and psychosocial trauma: Look earlier, look outside, and look beyond the persons. American Psychologist, 71, 187-198.

Comisión Interamericana de Derechos Humanos Informe n. ${ }^{\circ}$ 177/10. Caso 10.720

"Informe de fondo. OEA/ser/v/i1.140. doc. 75, 3 noviembre 2010". Original español. "Masacre de 'El Mozote y lugares aledaños'. El Salvador".

Comisión Nacional sobre la Desaparición de Personas (CONADEP) (1985). Nunca Más. Eudeba.

Corporación Nacional de Reparación y Conciliación (1996). Informe de la Comisión Nacional de la Verdad y Reconciliación. Corporación Nacional de Reparación y Conciliación.

Corte Interamericana de Derechos Humanos (2012). Masacre de El Mozote y lugares aledaños vs. El Salvador. Sentencia de 25 octubre de 2012 (Fondo, Reparaciones y Costas).

Cruz, J. M. (1997). Los factores posibilitadores y las expresiones de la violencia en los noventa. ECA, 588, 977-992.

Delgado, I. (2000). Introducción. En I. Delgado (Coord.). Impunidad y derecho a la memoria. De Pinochet a Timor. Sequitur.

Dobles, I. (2009). Memorias del dolor. Consideraciones acerca de las Comisiones de la Verdad en América Latina. Editorial Arlekín.

Flores, M., Molina, V. y Valle, C. (2010). Bienestar y trauma en lisiados y lisiadas de guerra afiliados a la Asociación de Lisiados de Guerra de El Salvador (ALGES), dieciocho años después del conflicto armado. Tesis de Grado. Departamento de Psicología. 
Universidad Centroamericana "José Simeón Cañas" (UCA).

Foa, E., Ehlers, A., Clark, D., Tolin, D. \& Orsillo, S. (1999). The Post-Traumatic Cognition Inventory (PTCI): Development and validation. Psychological Assessment, 11, 303-314.

Gaborit, M. (2006). Memoria histórica: relato desde las víctimas. Pensamiento Psicológico, 2, 7-20.

Gómez, D., Saburido, X., Pulido, M. y Couselo, M. (2000). La adaptación española de la escala de depresión IPAT: índices de fiabilidad. Geriatrika, 299-303.

González, D. (2009). Apuntes sobre la reparación judicial en el marco de la Ley de Justicia y Paz. En D. González, F. Perdomo y C. Mariño. Reparación judicial, principio de oportunidad e infancia en la Ley de Justicia y Paz (pp. 13-75). Deutsche Gesellschaft für Technische Zusammenarbeit GmbH (GTZ).

Griffin, B., Purcell, N. et al. (2019). Moral Injury: An Integrative Review. Journal of Traumatic Stress, 32, 350-362.

Halbwachs, M. (2004). La memoria colectiva. Prensas Universitarias de Zaragoza.

Henríquez, J.L. (1992). Los efectos psicosociales de la guerra en los niños de $\mathrm{El}$ Salvador. Revista de Psicología de El Salvador, 44, 89-107.

Hernández, P. y Blanco, A. (2005). Violencia política y trauma psicosocial. En A. Blanco, R. del Águila, y J. M. Sabucedo (Eds.). Madrid 11-M. Un análisis del mal y sus consecuencias (pp. 281-310). Trotta.

Instituto Latinoamericano de Salud Mental y Derechos Humanos (1994). Trauma psicosocial y adolescentes latinoamericanos: formas de acción grupal. ILAS.

Krug, S. E. \& Laughlin, J. E. (1976). Handbook for the IPAT Depression Scale. Institute for Personality and Ability Testing.
Leone, G. (2000). ¿Qué hay de "social" en la memoria? En A. Rosa, G. Bellelli y D. Bakhurst (Eds.). Memoria colectiva e identidad nacional (pp. 135-155). Biblioteca Nueva.

Lira, E. (1999). Mirando hacia atrás: un balance de 20 años de iniciativas en el Cono Sur. En P. Pérez (Ed.). Actuaciones psicosociales en guerra y violencia política [Psychosocial interventions in war and political violence] (pp. 139-166). Exlibris.

Lira, E. y Castillo, M. I. (1991). Psicología de la amenaza política y del miedo. ILAS.

Madariaga, C. (2002). Trauma psicosocial, trastorno de estrés postraumático y tortura. Ediciones CINTRAS

Martín-Baró, I. (1990). Psicología social de la guerra. UCA Editores.

Martín-Baró, I. (1998). Psicología de la liberación. Trotta.

Martín-Baró, I. (2003). Poder, ideología y violencia. Trotta.

Martín-Baró, I. (2016). El realismo crítico. Fundamentos y aplicaciones. UCA Editores.

Martín Beristáin, C. (1999). Reconstruir el tejido social. Icaria Antrazyt.

Moreno, F. (1991). Infancia y guerra en Centroamérica. FLACSO.

Naciones Unidas (1993). De la locura a la esperanza. La guerra de 12 años en El Salvador. Informe de la Comisión de la Verdad 1992-1993. Editorial ARCOIRIS.

Norris, F., Foster, J. \& Weissharr, D. (2002). The Epidemiology of Sex Differences in PTSD across Developmental, Societal, and Research Contexts. En R. Kimmerling, P. Ouimette \& J. Wolfe (Eds.). Gender and PTSD (pp. 3-42). The Guilford Press.

Norris, F., Friedman, M., Watson, P., Byrne, C., Díaz, E. \& Kaniasty, K. (2002). 60,000 Disasters Victims Speak: Part I. An Empirical Review of the Empirical Literature, 19812000. Psychiatry, 65, 207-239. 
Norris, F. \& Sloane, L. (2007). The Epidemiology of Trauma and PTSD. En J. Friedman, T. Keane y P. Resick (Eds.). Handbook of PTSD. Science and Practice (pp. 78-98). The Guilford Press.

Oficina de Derechos Humanos del Arzobispado de Guatemala (1998a). NUNCA MÁS II. Los mecanismos del horror. ODHAG.

Oficina de Derechos Humanos del Arzobispado de Guatemala (1998b). NUNCA MÁS I. Impactos de la violencia. ODHAG.

Pennebaker, J. (2003). Telling stories: The health benefits of disclosure. En J. M. Wilce (Ed.). Social and cultural lives of inmune systems (19-34). Routledge.

Pennebaker, J. y Crow, D. (2000). Memorias colectivas: la evolución y la durabilidad de la historia. En A. Rosa, G. Bellelli y D. Bakhurst (Eds.). Memoria colectiva $e$ identidad nacional (pp. 231-257). Biblioteca Nueva.

Peñarrubia, F. (2014). Círculo y centro. El grupo gestáltico. Ediciones La Llave.

Pimlott-Kubiat, S. y Cortina, L. (2003). Gender, victimization, and outcomes: Reconceptualizing risk. Journal of Consulting and Clinical Psychology, 71, 528-539.

Portillo, N. (2000). Juventud y trauma psicosocial en El Salvador. Estudios Centroamericanos, 618, 395-415.

Ruiz-Vargas, J. M. (2005). Recuerdos traumáticos: el enemigo interior. En A. Blanco, R. del Águila, y J. M. Sabucedo (Eds.). Madrid 11-M. Un análisis del mal y sus consecuencias (pp. 311-352). Trotta.

Ruiz-Vargas, J. M. (2010). Manual de Psicología de la memoria. Editorial Síntesis.

Sobrino, J. (1992). El principio misericordia. UCA Editores.

Sobrino, J. (2008). Fuera de los pobres no hay salvación. UCA Editores.

Vázquez, F. (2002). Construyendo el pasado: la memoria como práctica social. Estudios Centroamericanos, 649-650, 1049-1065.

Vázquez, N., Ibáñez, C. y Murguialday, C. (1996). Mujeres montaña. Vivencias de guerrilleras y colaboradoras del FMLN. HORAS.

Yáñez, M. A. (2002). Apoyo psicosocial en tiempos de oscuridad: una experiencia compartida en El Salvador. Estudios Centroamericanos, 649-650, 1103-1120.

Yáñez, M. S. (2010). Memoria histórica y Derechos Humanos: un camino de apoyo psicosocial después del conflicto armado en El Salvador. Tesis doctoral. Universidad del País Vasco.

Yáñez, M. S. (2013). Heridas abiertas. Atención psicosocial a víctimas de violaciones de Derechos Humanos. Ministerio de Salud. 